\title{
Estudo do sistema de drenagem urbana localizado na avenida José Caetano de Almeida, Quixadá/CE
}

\author{
Study of the urban drainage system located on Avenida \\ José Caetano de Almeida, Quixadá / CE
}

\section{Estudio del sistema de desagüe urbano ubicado en la avenida José Caetano de Almeida, Quixadá/CE}

\section{Étude du système de drainage urbain situé sur l'Avenue José Caetano de Almeida, à Quixadá/CE}

Clarissa Patrizia de Melo Freitas Almeida clarissapatrizia.dmelo@gmail. com

Faculdade Cisne de Quixadá

José Wémenson Rabelo Chaves iD

wemensonrabelo@gmail.com Faculdade Cisne de Quixadá

Maria Jorgiana Ferreira Dantas

jorgianaferreira@hotmail.com Universidade Estadual de São Paulo - Unesp

\section{Resumo}

A crescente urbanização, aliada à falta de planejamento urbano, trouxe um dos grandes problemas para o escoamento da água, que é a impermeabilização do solo. A impermeabilização decorrente da ocupação urbana altera o ciclo hidrológico, resultando em um aumento de alagamentos urbanos, causando desconforto para os moradores e degradação das águas pluviais. Uma das estruturas que compõem o sistema de saneamento é a drenagem urbana, que possui grande importância para o funcionamento do meio urbano, ajudando a drenar de forma satisfatória as águas pluviais. Diante desse contexto, este trabalho teve como objetivo estudar o sistema de microdrenagem urbana da avenida José Caetano de Almeida, do bairro Combate, na cidade de Quixadá-CE. Para isso, avaliou-se in loco os dispositivos que compõem o sistema de drenagem pluvial da avenida, verificando a presença de manifestações patológicas e seus agentes causadores. Não se dizer que o atual projeto existente na avenida não tem funcionalidade, pois o mesmo está em funcionamento há muitos anos sem manutenção e não foi concluído, tornando-o falho perante os demais. Ao verificar os dispositivos de drenagem e suas respectivas manifestações patológicas e agentes causadores, foram propostas estratégias para melhoria da região através de arborização, telhado verde e utilização de pavimentos permeáveis.

Palavras-chave: Escoamento superficial. Impacto da urbanização. Saneamento básico.

\begin{abstract}
The growing urbanization combined with the lack of urban planning has brought about one of the major problems for the flow of water, the waterproofing of the soil. The waterproofing resulting from urban occupation changes the hydrological cycle, resulting in an increase in urban flooding, causing discomfort for residents and degradation of rainwater. One of the structures that make up the sanitation system is urban drainage, which has great importance for the functioning of the urban environment, helping to drain rainwater in a satisfactory way. Given this context, this study aimed to analyze the urban micro-drainage system of Avenida José Caetano de Almeida, in the combate neighborhood, in the city of Quixadá$\mathrm{CE}$. The devices that make up the avenue's rain drainage system were evaluated in loco, checking for the presence of pathological manifestations and their causative agents. The current project on the avenue cannot be accused of lack of functionality, as it has been in operation for many years without maintenance and has not been completed, making it flawed in front of the others. When checking the drainage devices and their respective pathological manifestations and causative agents, improvement strategies for the region were proposed through afforestation, green roof and the use of permeable pavements.
\end{abstract}

Keywords: Surface runoff. Impacts of urbanization. Sanitation. 


\section{Resumen}

La creciente urbanización aliada a la falta de planificación urbana trajo uno de los grandes problemas para el desagüe que es la impermeabilización del suelo. La impermeabilización del suelo debido a la ocupación urbana altera el ciclo hidrológico, resultando en un aumento de inundaciones urbanas, causando incomodidad para los residentes y degradación de las aguas pluviales. Una de las estructuras que componen el sistema de saneamiento es el drenaje urbano, que posee gran importancia para el funcionamiento del medio urbano, ayudando a drenar de forma satisfactoria las aguas pluviales. Ante ese contexto, este trabajo tuvo como objetivo estudiar el sistema de micro drenaje urbano de la Avenida José Caetano de Almeida, del barrio Combate, en la ciudad de Quixadá- CE. Para eso, fue evaluado in loco los dispositivos que componen el sistema de drenaje pluvial de la avenida, verificando la presencia de manifestaciones patológicas y sus agentes causadores. No se puede acusar el actual proyecto existente en la avenida por falta de funcionalidad, porque el mismo está en funcionamiento a muchos años sin mantenimiento y no fue concluido, volviéndolo fallo ante los demás. Al verificar los dispositivos de drenaje y sus respectivas manifestaciones patológicas y sus agentes causadores, fueron propuestas estrategias de mejoría para la región por medio de reforestación, tejado verde y utilización de suelos permeables.

Palabras-clave: Drenaje superficial. Impacto da urbanización. Saneamiento básico.

\section{Résumé}

L'urbanisation croissante combinée à l'absence de planification urbaine a apporté l'un des plus grands problèmes pour l'écoulement de l'eau : l'imperméabilisation du sol. L'imperméabilisation résultant de l'occupation urbaine modifie le cycle hydrologique, et cause une augmentation des inondations urbaines, ce qui est désagréable pour les résidents et dégrade des eaux pluviales. L'une des structures qui composent le système d'assainissement est le drainage urbain, qui a une grande importance pour le fonctionnement de l'environnement urbain, puisqu'il aide à drainer de manière satisfaisante l'eau de pluie. Dans ce contexte, cette étude visait à étudier le système de petit réseau de drainage urbain de l'Avenue José Caetano de Almeida, dans le quartier de Combate, dans la ville de Quixadá, au Brésil. Pour cela, on a fait un contrôle sur place des dispositifs qui font partie du système de drainage de la pluie dans l'avenue, à partir de la vérification de la présence de manifestations pathologiques et de leurs agents causatifs. On ne peut pas accuser le projet actuel existant sur l'avenue d'absence de fonctionnalité, parce qu'il est en opération - sans maintenance - il y a de nombreuses années. De plus, il n'a pas été achevé, ce qui le rend défectueux devant les autres. Lors de la vérification des dispositifs de drainage et de leurs manifestations pathologiques et leurs respectifs agents causals, des stratégies d'amélioration ont été proposées pour la région : c'est-à-dire, le boisement, le toit vert et l'utilisation de chaussées perméables.

Mots-clés: Écoulement de surface. Impact de l'urbanisation. Assainissement.

\section{Introdução}

O processo de urbanização teve início no Brasil a partir da Revolução Industrial, no século XX, trazendo mudanças no cenário demográfico com o deslocamento da população da área rural para a área urbana. $\mathrm{O}$ crescente aumento descontrolado da população ocasionou vários transtornos: além da má infraestrutura e organização, a ausência dos sistemas de redes de esgoto, de drenagem urbana, hidráulico e de iluminação para atender às necessidades básicas (SANTOS, 1998).

De acordo com a Lei n. 11.445/2007, que institui as diretrizes para as instalações operacionais federais de saneamento básico, o setor é responsável por promover uma melhor qualidade de vida da população, tendo em vista que suas medidas são de prevenir doenças, propiciando uma maior higiene social e preservando o 
meio ambiente. Nele estão inseridos os sistemas de abastecimento de água potável, tratamento de esgoto, coleta e disposição dos resíduos sólidos e drenagem urbana e manejo das águas pluviais. O saneamento básico é um direito assegurado pela constituição, mas é perceptível o atraso das cidades brasileiras em relação à implantação desse sistema.

A drenagem urbana é o conjunto de estruturas e instalações que tem como finalidade o transporte, retenção e disposição final dos efluentes oriundos das águas pluviais. Objetiva evitar o acúmulo de águas das chuvas em locais prejudiciais, que podem causar alagamentos, enxurradas e degradação do pavimento ( $\mathrm{TUCCl}$, 2008), sendo essas estruturas classificadas em dois tipos: a microdrenagem - responsável por coletar as águas superficiais e subterrâneas por meio de sarjetas, guias, bocas de lobo, poços de visitas, ramais condutores; e a macrodrenagem - destinada a transportar as águas coletadas pela a microdrenagem através de galerias, bueiros, reservatório de detenção, dissipadores de energia e outras obras complementares (DRUMOND, 2012).

Conforme o Instituto Brasileiro de Geografia e Estatística (IBGE, 2019), as regiões Norte e Nordeste permanecem abaixo da média nacional no quesito abastecimento de água, esgotamento sanitário, drenagem urbana e coleta de lixo. Tendo em vista essa problemática, a Pesquisa Nacional de Saneamento Básico (PNSB, 2008), que avalia na esfera nacional a qualidade dos serviços de saneamento básico prestados por prefeituras municipais e empresas contratadas em convênio com o Ministério das Cidades, verificou que os problemas concernentes da urbanização tinham apresentado algumas melhorias significativas, todavia algumas dificuldades são observadas, principalmente no âmbito social e ambiental.

É observado, no município de Quixadá-CE, que a situação é problemática com relação à falta de planejamento e desenvolvimento de projetos com uma visão ambiental urbana de forma integrada por parte do órgão específico para controle dessas atividades. Um dos vários problemas enfrentados nesse contexto é a impermeabilização excessiva do solo, com áreas cobertas por pavimento flexível, o que dificulta a infiltração da água da chuva, resultante de um mau uso e ocupação do solo.

Desde o ano 2000, com a criação do Plano Diretor, já era notório que a cidade tinha um precário sistema de drenagem, havendo alguns pontos críticos, como a região do bairro Combate, que vai da rodoviária à lagoa do Bispo, na avenida José Caetano de Almeida, objeto de estudo deste trabalho.

Na avenida José Caetano de Almeida, na cidade de Quixadá - CE, são notórios os constantes transtornos causados pelas chuvas. Ao longo desses 19 anos, desde a última atualização do plano diretor do município, no ano 2000 , que o projeto contém o sistema de saneamento básico da cidade, inclusive o de sistema de rede de drenagem urbana, que visava reverter o problema de alagamento na região.

Observa-se uma urbanização mal concebida na região da avenida José Caetano de Almeida, causando transtornos devido a sua ineficiência. As construções foram edificadas (casas e comércios), sobre uma estrutura que recebe grande quantidade de água. Estrutura que, visualmente, já vem sofrendo as intempéries climáticas e físicas. Quando chove, as águas pluviais não escoam corretamente, causando alagamentos e inundações. Com isso, na situação em que ela está hoje, pode ser um grande risco para os habitantes dessa região quando há maior precipitação de chuva.

Portanto, a presente pesquisa tem como objetivo averiguar o atual sistema de drenagem da avenida José Caetano de Almeida, do bairro Combate, na cidade de Quixadá-CE, por meio de avaliação in loco dos dispositivos de drenagem, verificando a presença de manifestações patológicas e seus agentes causadores, além de propor estratégias para uma melhor gestão da água no espaço urbano da cidade.

\section{Metodologia}

Neste trabalho, foi feito um estudo bibliográfico, através de sites, jornais, plano diretor, periódicos, dissertações e teses sobre o assunto. A metodologia consistiu na caracterização da área em estudo, mostrando os aspectos populacionais, climáticos e hidrográficos, bem como o diagnóstico dos dispositivos de microdrenagem urbana levantados em campo, com fotografias e dados obtidos na prefeitura da cidade. 


\section{1 Área de estudo}

O município de Quixadá está localizado no sertão central do estado do Ceará (Figura 1). É a maior cidade da região, com uma área de 2.019,834 km2 e uma população estimada, em 2019, de 87,728 habitantes, conforme o IBGE (2019). Possui clima tropical quente semiárido e território com relevos do tipo depressões sertanejas e maciços residuais (IPECE, 2017)

Figura 1 - Mapa de localização do município de Quixadá-CE

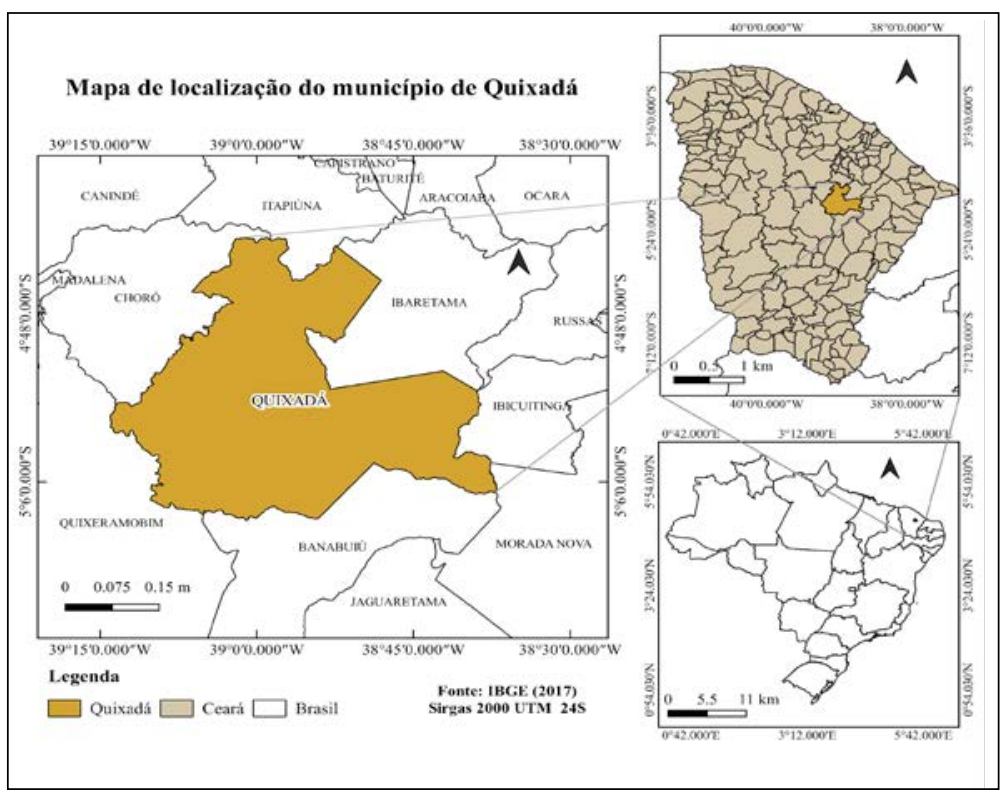

Fonte: Os autores (2019).

A maior parte do município está situada na bacia hidrográfica do rio Sitiá, fazendo parte da sub-bacia do rio Banabuiú, como mostra a Figura 2, uma das cinco sub-bacias que compõem a Bacia do Jaguaribe. A sua outra parte se divide entre as bacias do rio Piranji e Choro (IPECE, 2017).

Figura 2 - Municípios contidos na sub-bacia do Rio Banabuiú

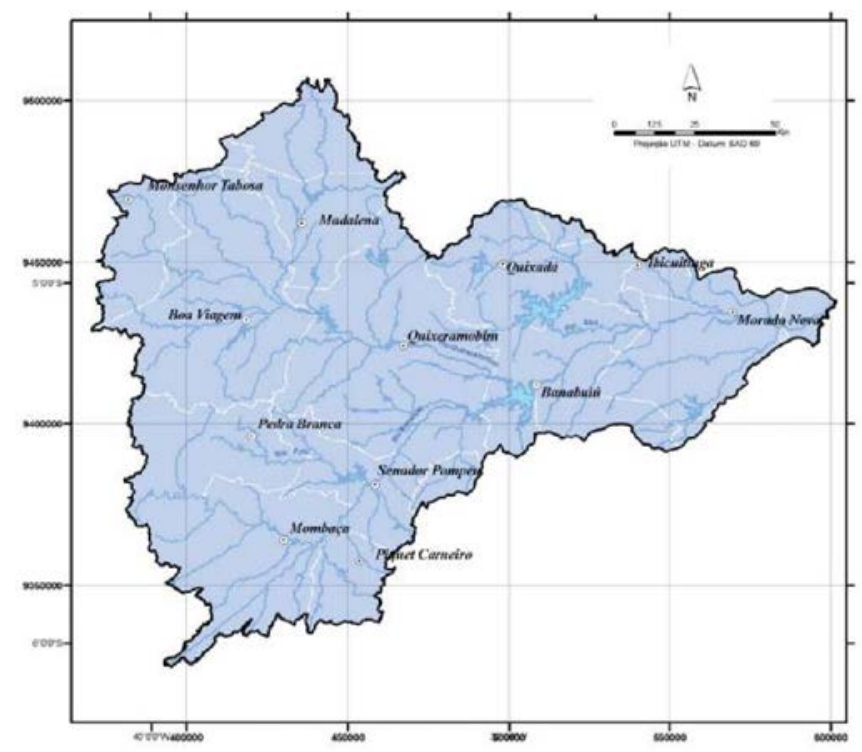

Fonte: Pacto das Águas (2009). 
Conforme mostra a Tabela 1, as precipitações se concentram, principalmente, entre os meses de fevereiro e maio, sendo março o mês com as maiores precipitações, enquanto setembro e agosto são os períodos mais secos. As temperaturas médias apresentam diferença de $1,70^{\circ}$ ao longo do ano.

Tabela 1 - Dados climatológicos de Quixadá entre os anos de 1982 e 2012

\begin{tabular}{l|c|c|c|c|c|c|c|c|c|c|c|c}
\hline Mês & Jan. & Fev. & Mar. & Abr. & Mai. & Jun. & Jul. & Ago. & Set. & Out. & Nov. & Dez. \\
\hline Temperatura média $\left({ }^{\circ} \mathrm{C}\right)$ & 27,9 & 27,4 & 26,9 & 26,7 & 26,4 & 26,2 & 26,2 & 26,7 & 27,2 & 27,7 & 27,9 & 27,9 \\
Temperatura mínima $\left({ }^{\circ} \mathrm{C}\right)$ & 22,1 & 21,9 & 21,9 & 21,8 & 21,5 & 20,7 & 20,5 & 20,4 & 20,8 & 21,2 & 21,6 & 22,0 \\
Temperatura máxima $\left({ }^{\circ} \mathrm{C}\right)$ & 33,7 & 33,0 & 32,0 & 31,6 & 31,4 & 31,7 & 32,0 & 33,0 & 33,7 & 34,2 & 34,3 & 33,9 \\
Chuva $(\mathrm{mm})$ & 64 & 107 & 188 & 179 & 110 & 53 & 30 & 5 & 2 & 2 & 6 & 19 \\
\hline
\end{tabular}

Fonte: Adaptado de Climate-data.org (2019).

O município de Quixadá tem a quarta maior média anual de precipitação pluviométrica da sub-bacia de Banabuiú, no entanto possui o segundo maior deflúvio médio anual e o maior potencial de evapotranspiração da região, conforme se observa na Tabela 2.

Tabela 2 - Caracterização hidrológica dos municípios da sub-bacia do rio Banabuiú.

\begin{tabular}{l|c|c|c|c}
\hline Município & $\begin{array}{c}\text { Precipitação pluvio- } \\
\text { métrica média anual } \\
(\mathrm{mm})\end{array}$ & $\begin{array}{c}\text { Deflúvio médio } \\
\text { anual }(\mathrm{mm})\end{array}$ & $\begin{array}{c}\text { Volume escoado } \\
\text { médio anual (hm3) }\end{array}$ & $\begin{array}{c}\text { Evapotranspiração } \\
\text { potencial (mm) }\end{array}$ \\
\hline Banabuiú & 815 & 62 & 66 & 1929 \\
Boa Viagem & 703 & 59 & 156 & 2023 \\
Ibicuitinga & 974 & 65 & 24 & 1933 \\
Itaira & 720 & 45 & 28 & 1933 \\
Limoeiro do Norte & 682 & 58 & 21 & 2093 \\
Madalena & 816 & 59 & 127 & 1929 \\
Monsenhor Tabosa & 646 & 77 & 65 & 2080 \\
Morada Nova & 742 & 65 & 200 & 1933 \\
Pedra Branca & 853 & 70 & 37 & 1943 \\
Piquet Carneiro & 897 & 66 & 188 & 1886 \\
Quixadá & 838 & 62 & 229 & 2093 \\
Quixeramobim & 707 & 59 & 2093 \\
Senador Pompeu & 730 & & & 1927 \\
\hline
\end{tabular}

Fonte: Funceme (2019).

Segundo dados apresentados pelo IBGE (2010), Quixadá apresenta 52,7\% de domicílios com esgotamento sanitário adequado, 84,8\% de domicílios urbanos em vias públicas com arborização e 10,3\% de domicílios urbanos em vias públicas com urbanização adequada (presença de bueiro, calçada, pavimentação e meiofio). Quando comparado com os outros 184 municípios do estado, fica na posição $12^{\circ}, 123^{\circ}$ e $29^{\circ}$ de 184 , respectivamente. Já quando comparada a outras 5.570 cidades do Brasil, sua posição é $2.117^{\circ}, 1997^{\circ} \mathrm{e}$ $2770^{\circ}$, respectivamente

\subsection{Caracterização da área específica do estudo}

A avenida José Caetano de Almeida, como pode ser identificado na Figura 3, tem seu início no cruzamento com a avenida Plácido Castelo e termina na Avenida Francisco Pinheiro de Almeida, com 1,2 km de extensão. Em visita feita ao local, foi contabilizado um total de 154 pontos residenciais e 46 estabelecimentos comerciais. 
Figura 3 - Localização da avenida José Caetano de Almeida, Quixadá/CE

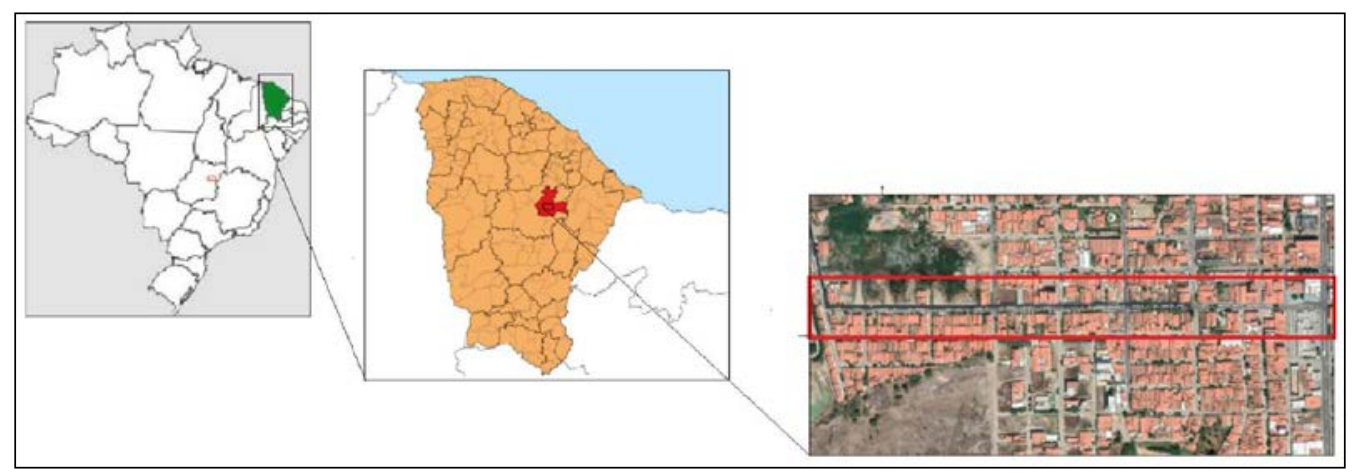

Fonte: Os autores (2019).

A via em estudo é a principal rota de percurso para o terminal rodoviário de Quixadá, recebendo um constante fluxo de veículos, tais como ônibus, carros e caminhões, interligando a sede da cidade às demais regiões do município e do estado. Em decorrência desse fator, os dispositivos da via recebem diretamente o peso bruto transmitido pelos eixos dos veículos.

As Figuras $4 \mathrm{a}$ e 4b, mostram os constantes alagamentos que as chuvas causam na avenida José Caetano de Almeida, sendo um problema recorrente, ocorrendo em diferentes anos consecutivos (2017, 2018 e 2019). De acordo com a matéria do jornal Diário do Nordeste (2017), o problema persiste há mais de duas décadas, e cerca de apenas 20 minutos de precipitação foi suficiente para causar diversos transtornos aos moradores e motoristas que ali trafegavam.

Figura 4 - Avenida José Caetano de Almeida alagada após chuvas ocorridas, em (a) dia 6 de março de 2017 e em (b) dia 5 de dezembro de 2018.
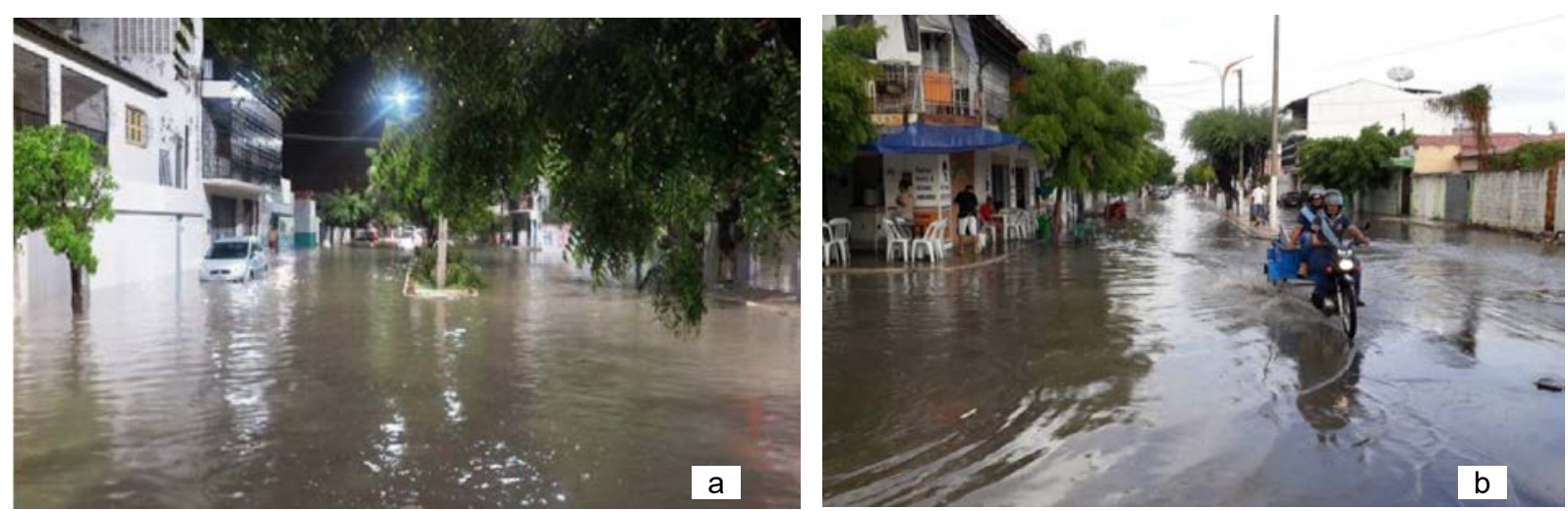

Fonte: Sertão alerta (2018).

\subsection{Diagnóstico dos dispositivos de drenagem}

As visitas ao local de estudo ocorreram nos dias 24 e 25 de maio de 2019. Durante o levantamento in loco, foram levantadas as características dos dispositivos de drenagem que compõem a microdrenagem, como bocas de lobo e poços de visitas existentes, observando a existências de manifestações patológicas, além de registros fotográficos e coleta das coordenadas geográficas. A partir desses dados, elaborou-se uma tabela com a localização dos dispositivos em relação às ruas que cruzam a avenida. Para desenvolvimento deste trabalho, foi solicitado aos órgãos municipais o atual projeto de drenagem urbana da avenida José Caetano de Almeida contudo não foi disponibilizado o projeto por completo. 


\section{Resultados e discussão}

Há que se mostrar os resultados que foram encontrados, por meio da análise dos dados coletados, em etapa anterior à pesquisa. Nesta seção, apresenta-se o estudo de caso, realizado no ano de 2019, com o objetivo de se efetuar uma análise sobre a drenagem de águas pluviais da avenida José Caetano de Almeida, em Quixadá/CE. As informações utilizadas no estudo foram extraídas, principalmente, de informações inerentes ao plano diretor do município, de dados coletados em campo por meio de visita in loco, bem como de relatos em experiência dos moradores do local avaliado. Ademais, todas essas prerrogativas foram demonstradas, por meio de gráficos, figuras, tabelas e quadros.

\subsection{Análise do projeto existente}

Foi realizado um estudo do atual projeto de drenagem urbana da avenida, fornecido pela prefeitura nos formatos .DWG e .PDF. A partir dessa pesquisa, foi constatado que o número de dispositivos encontrados na via é menor do que o de projeto, pois, de acordo com o projeto, deveriam existir 20 dispositivos do tipo boca de lobo na avenida, no trecho entre a Rui Maia e a Plácido Castelo (Figura 5), no entanto só existem 15, como mostra a Figura 6.

Figura 5 - Planta baixa do sistema de drenagem com localização dos dispositivos no projeto

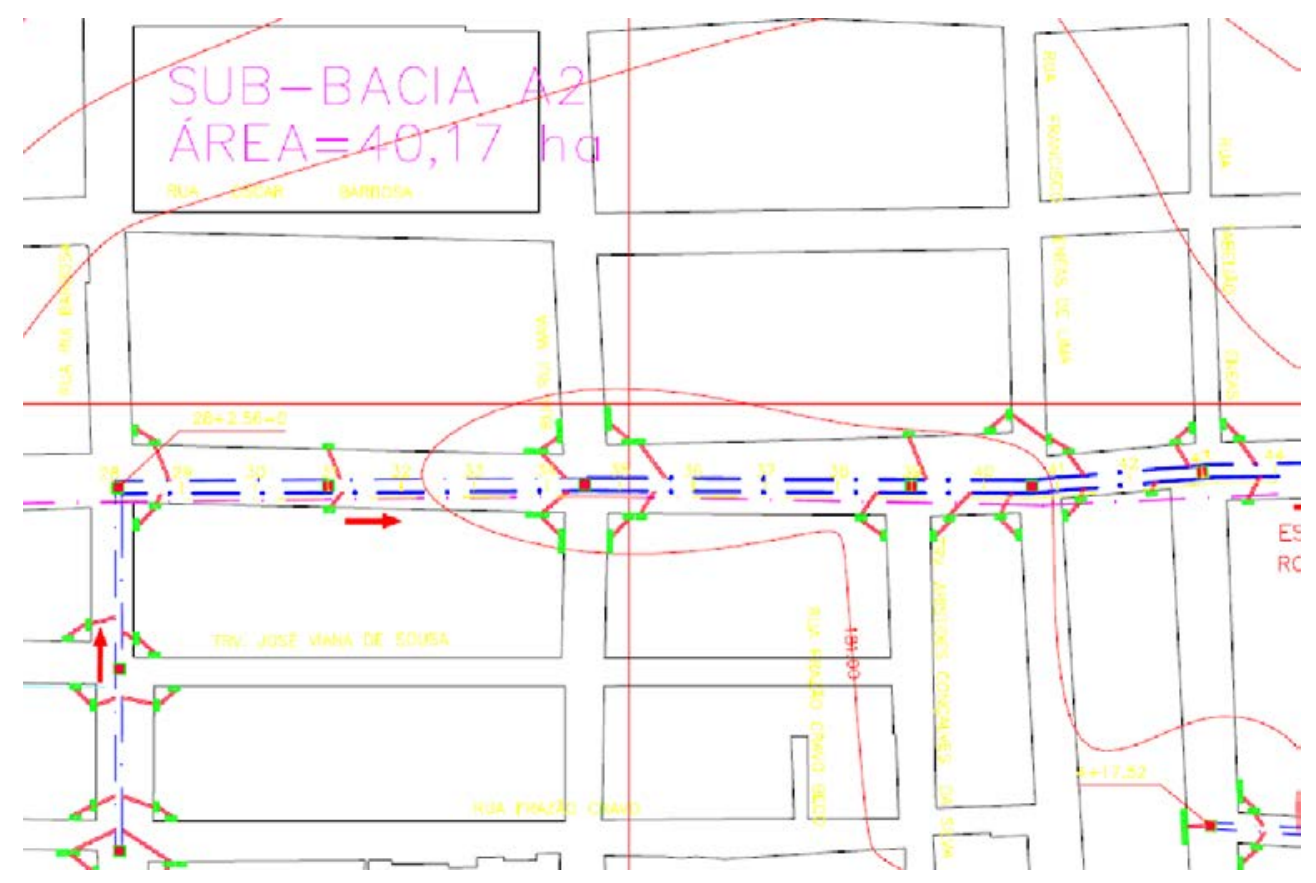

Fonte: Plano Diretor da Prefeitura Municipal de Quixadá (2000).

É importante salientar que o projeto executivo proposto no ano de 2020 sofreu modificações em seus elementos de drenagem, no quesito quantidade de dispositivos, durante a fase de execução. Essa redução pode sobrecarregar o sistema de microdrenagem no decorrer das precipitações, prejudicando a interceptação, captação e condução das águas pluviais que escoam na superfície da avenida, provocando o acúmulo de água e alagamento nos locais indesejados da via. 
Figura 6 - Localização das bocas de lobo existentes na avenida em estudo

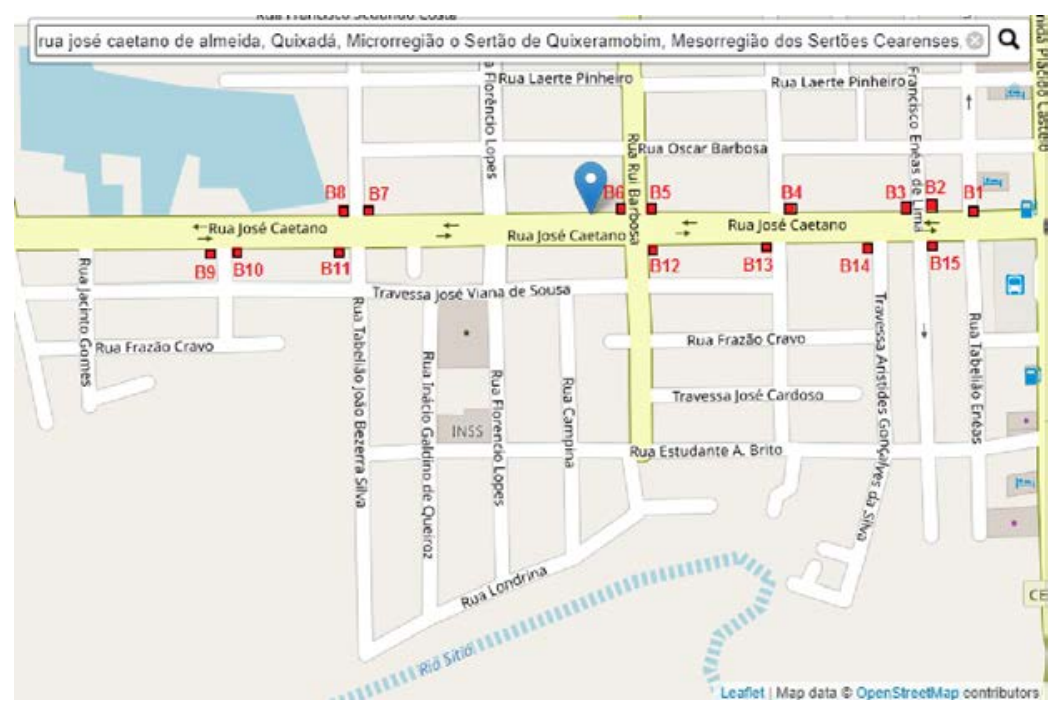

Fonte: Os autores (2019).

Os dispositivos encontrados na avenida foram tabulados de acordo com o sentido da via em que foram averiguados, com suas coordenadas e respectivas nomenclaturas, conforme a Tabela 3. As 15 bocas de lobo existentes em toda a avenida estão em mau estado de conservação, em sua maioria apresentando manifestações patológicas, obstrução por vegetação ou resíduos sólidos (lixo).

Tabela 3 - Localização e coordenadas das bocas de lobo.

\begin{tabular}{|c|c|c|}
\hline Bocas de lobo & Localização & Coordenadas \\
\hline B1 & $\begin{array}{l}\text { Av. José Caetano de Almeida com rua Tabelião Enéas, sentido F.co Pinheiro de } \\
\text { Almeida. }\end{array}$ & $\begin{array}{l}4^{\circ} 58^{\prime} 20.789^{\prime \prime} \mathrm{S} \\
39^{\circ} 1^{\prime} 0.351^{\prime \prime} \mathrm{W}\end{array}$ \\
\hline B2 & $\begin{array}{l}\text { Av. José Caetano de Almeida com rua Francisco Enéas, sentido F.co Pinheiro } \\
\text { de Almeida. }\end{array}$ & $\begin{array}{c}4^{\circ} 58^{\prime} 20.920^{\prime \prime} \mathrm{S} \mathrm{39 \circ} \\
1^{\prime} 2.133^{\prime \prime} \mathrm{W}\end{array}$ \\
\hline B3 & $\begin{array}{l}\text { Av. José Caetano de Almeida com rua Francisco Enéas, sentido F.co Pinheiro } \\
\text { de Almeida. }\end{array}$ & $\begin{array}{c}4^{\circ} 58^{\prime} 20.766^{\prime \prime} \mathrm{S} 39^{\circ} \\
1^{\prime} 2.211^{\prime \prime} \mathrm{W}\end{array}$ \\
\hline B4 & Av. José Caetano de Almeida com rua Rui Maia, sentido F.co Pinheiro de Almeida. & $\begin{array}{c}4^{\circ} 58^{\prime} 20.766^{\prime \prime} \mathrm{S} \mathrm{39 \circ} \\
1^{\prime} 5.806 " \mathrm{~W}\end{array}$ \\
\hline B5 & $\begin{array}{l}\text { Av. José Caetano de Almeida com rua Rui Barbosa, sentido F.co Pinheiro de } \\
\text { Almeida. }\end{array}$ & $\begin{array}{c}4^{\circ} 58^{\prime} 20.789^{\prime \prime} \mathrm{S} 39^{\circ} \\
1^{\prime} 10.028 \text { " W }\end{array}$ \\
\hline B6 & $\begin{array}{l}\text { Av. José Caetano de Almeida com rua Rui Barbosa, sentido F.co Pinheiro de } \\
\text { Almeida. }\end{array}$ & $\begin{array}{l}4^{\circ} 58^{\prime} 20.597^{\prime \prime} \mathrm{S} \\
39^{\circ} 1 \text { '10.463" W }\end{array}$ \\
\hline B7 & $\begin{array}{l}\text { Av. José Caetano de Almeida com rua Tabelião João Bezerra, sentido F.co } \\
\text { Pinheiro de Almeida. }\end{array}$ & $\begin{array}{c}4^{\circ} 58^{\prime} 20.905^{\prime \prime} \mathrm{S} 39^{\circ} \\
1^{\prime} 18.115^{\prime \prime} \mathrm{W}\end{array}$ \\
\hline B8 & $\begin{array}{l}\text { Av. José Caetano de Almeida com rua Tabelião João Bezerra, sentido F.co } \\
\text { Pinheiro de Almeida. }\end{array}$ & $\begin{array}{c}4^{\circ} 58^{\prime} 20.866^{\prime \prime} \mathrm{S} \mathrm{39 \circ} \\
\text { 1' } 18.615^{\prime \prime} \mathrm{W}\end{array}$ \\
\hline B9 & $\begin{array}{l}\text { Av. José Caetano de Almeida com rua José Capistrano, sentido avenida Plácido } \\
\text { Castelo. }\end{array}$ & $\begin{array}{c}4^{\circ} 58^{\prime} 21.528^{\prime \prime} \mathrm{S} 39^{\circ} \\
1^{\prime} 22.367^{\prime \prime} \mathrm{W}\end{array}$ \\
\hline B10 & $\begin{array}{l}\text { Av. José Caetano de Almeida com rua José Capistrano, sentido avenida Plácido } \\
\text { Castelo. }\end{array}$ & $\begin{array}{c}4^{\circ} 58^{\prime} 21.559^{\prime \prime} \mathrm{S} \mathrm{39 \circ} \\
1 \text { ' } 21.936 " \mathrm{~W}\end{array}$ \\
\hline B11 & $\begin{array}{l}\text { Av. José Caetano de Almeida com rua Frazão Cravo, sentido avenida Plácido } \\
\text { Castelo. }\end{array}$ & $\begin{array}{l}4^{\circ} 58^{\prime} 21.520^{\prime \prime} \mathrm{S} 39^{\circ} \\
1^{\prime} 18.539 " \mathrm{~W}\end{array}$ \\
\hline B12 & $\begin{array}{l}\text { Av. José Caetano de Almeida com rua Rui Barbosa, sentido avenida Plácido } \\
\text { Castelo. }\end{array}$ & $\begin{array}{c}4^{\circ} 58^{\prime} 21.420^{\prime \prime} \mathrm{S} 39^{\circ} \\
1^{\prime} 9.968 " \mathrm{~W}\end{array}$ \\
\hline B13 & Av. José Caetano de Almeida com rua Rui Maia, sentido avenida Plácido Castelo. & $\begin{array}{c}4^{\circ} 58^{\prime} 21.305^{\prime \prime} \mathrm{S} 39^{\circ} \\
1^{\prime} 6.365^{\prime \prime} \mathrm{W}\end{array}$ \\
\hline B14 & $\begin{array}{l}\text { Av. José Caetano de Almeida com rua Travessa Aristides, sentido avenida Plácido } \\
\text { Castelo. }\end{array}$ & $\begin{array}{c}4^{\circ} 58^{\prime} 21.336^{\prime \prime} \mathrm{S} 39^{\circ} \\
\text { 1' } 3.287^{\prime \prime} \mathrm{W} \\
\end{array}$ \\
\hline B15 & $\begin{array}{l}\text { Av. José Caetano de Almeida com rua Francisco Enéas, sentido avenida Plácido } \\
\text { Castelo. }\end{array}$ & $\begin{array}{c}4^{\circ} 58^{\prime} 21.251^{\prime \prime} \mathrm{S} 39^{\circ} \\
1,1.881^{\prime \prime} \mathrm{W}\end{array}$ \\
\hline
\end{tabular}

Fonte: Os autores (2019). 


\subsection{Manifestações patológicas}

Foram encontrados nos dispositivos que compõem a microdrenagem pluvial da avenida diversas manifestações patológicas, como desgaste com o tempo, erosões e entupimentos devido aos acúmulos de resíduos variados. Essas patologias sobrecarregam o sistema de rede de drenagem.

\subsubsection{Desgaste com o tempo}

Em diversas bocas de lobo é possível notar o efeito do desgaste em decorrência do tempo, conforme mostra a Figura 7. Essa deterioração foi observada em vários dispositivos de drenagem, tratando-se uma manifestação patológica comum no sistema de microdrenagem. Umas das principais causas desses desgastes são o constante recebimento de cargas transmitidas dos eixos dos automóveis e a inexistência de manutenções corretivas e periódicas. Esses fatores, quando associados, intensificam uma rápida deterioração nos dispositivos, não exercendo a finalidade para a qual foi projetado.

Figura 7 - Bocas de lobo com desgaste do decorrer do tempo

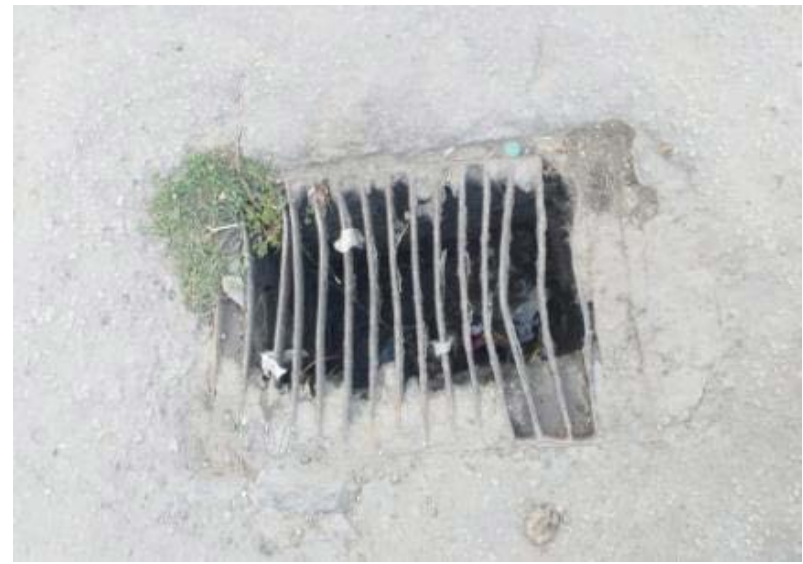

Boca de lobo B1

Fonte: Os autores (2019).

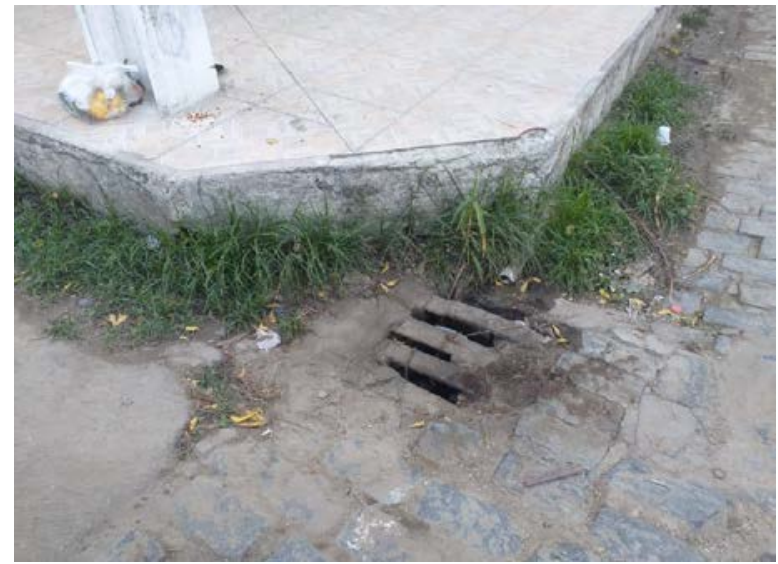

Boca de lobo B2

\subsubsection{Erosões}

As erosões podem ser causadas por inúmeros fatores, sendo um deles a construção errônea do sistema de drenagem, principalmente dos dispositivos da microdrenagem, levando-o ao desmoronamento. Até mesmo o peso oriundo dos automóveis que estacionam em cima ou nas extremidades das bocas de lobo causam desgaste com o tempo, e surgem erosões.

A Figura 8 mostra uma boca de lobo com erosões, além de descaso e falta de manutenção. Diante do estado de deterioração dos dispositivos, os moradores colocaram pedras em cima, na tentativa de impedir acidentes e entrada das rodas veículos ou quaisquer outros objetos. 
Figura 8- Boca de lobo B8 apresentando erosões.

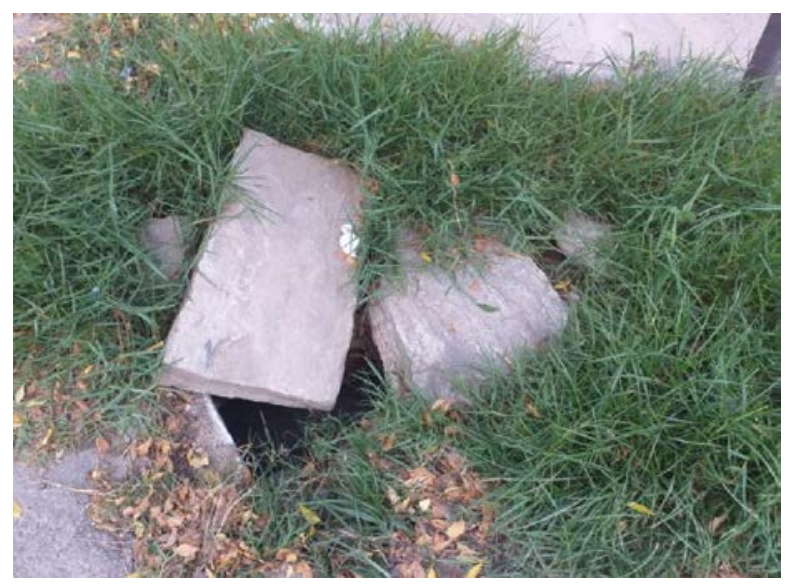

Fonte: Os autores (2019).

Esse problema encontra-se no dispositivo B8, localizado na avenida José Caetano de Almeida com rua Tabelião João Bezerra, sentido Francisco Pinheiro de Almeida, esse problema pode ser resolvido com a remoção da vegetação, matéria orgânica e solo, que está por cima e em volta do dispositivo. Além disso, deve ser feita a limpeza interna da boca de lobo para remover o material sedimentar que, devido à erosão, está obstruindo o dispositivo. Em seguida, a entrada deve ser reconstruída de tal forma a evitar que o fenômeno ocorra novamente.

\subsubsection{Entupimentos}

Os problemas causados pelo descarte irregular do lixo e pela falta de limpeza regular da via comprometem a qualidade e a eficiência das redes de drenagem (Figura 9). No período de chuvas, esse problema se torna mais frequente, pois um amplo volume de lixo é transportado para a rede, causando transtornos por meio de alagamentos e refluxo nas redes de esgoto.

Figura 9 - Boca de lobo B3 entupida por resíduos sólidos (lixo)

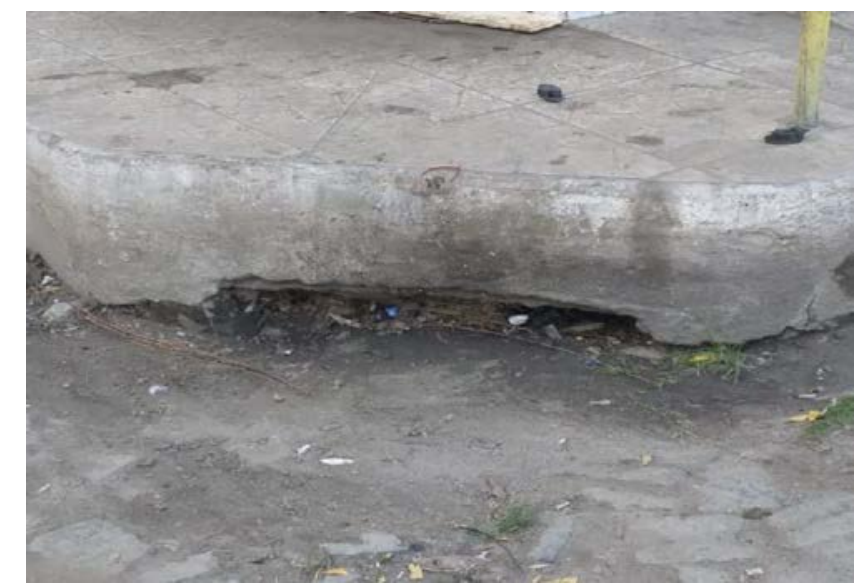

Fonte: Os autores (2019).

As Figura 9a e 9b, respectivamente, apresentam o problema mais encontrado, o de entupimento das bocas de lobo pela vegetação. Esse problema é prejudicial para o sistema de drenagem, pois, durante as precipitações, a capacidade de captação e direcionamento das águas das chuvas se sobrecarregam, especialmente devido à quantidade reduzida de dispositivos. 
Figura 10 - Bocas de lobo obstruídas devido ao crescimento da vegetação no entorno. Em (a) boca de lobo B15 e em (b) boca de lobo B9.
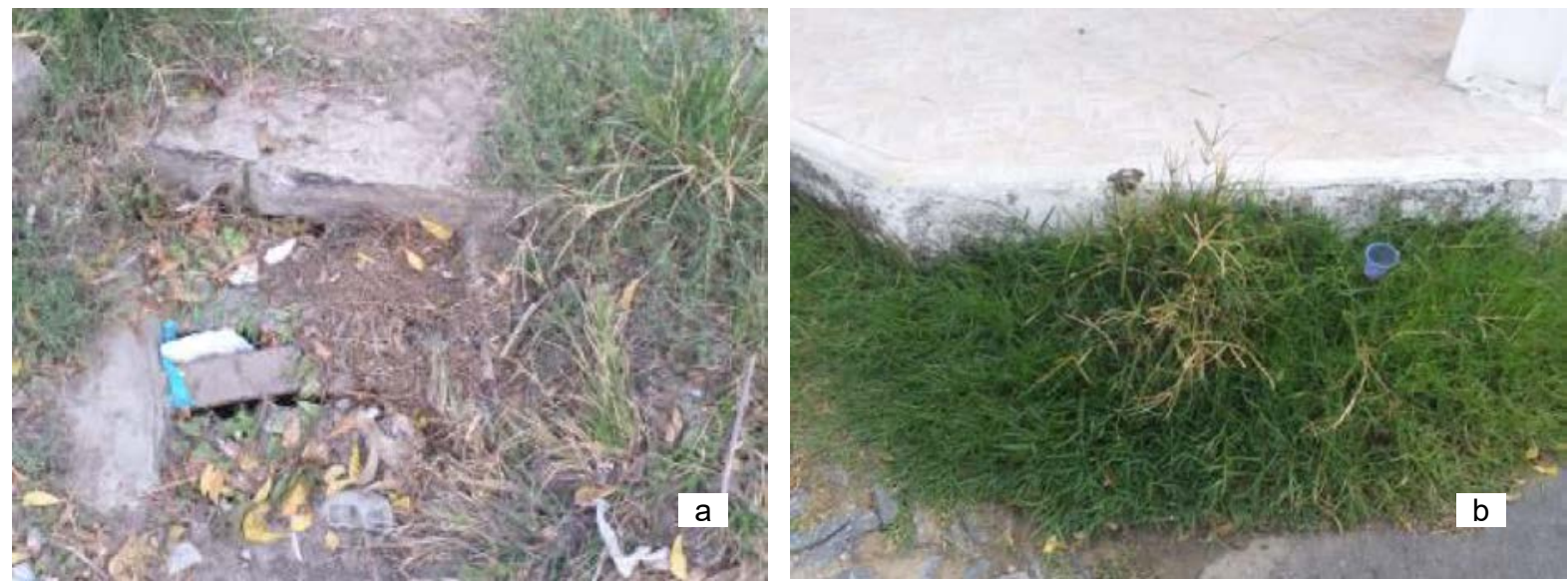

Fonte: Os autores (2019).

A Figura 11 ilustra que nem todos os problemas de entupimento têm a mesma origem. Nesse caso, por exemplo, alguns dispositivos encontram-se praticamente todo obstruído devido à má execução da obra de pavimentação e do passeio. O acúmulo de sujeira em suas barras aumenta com a passar do tempo, obstruindo ainda mais o dispositivo.

Figura 11 - Bocas de lobo com problemas de obstrução devido à pavimentação e do passeio. Em (a) boca de lobo B11 e em (b) boca de lobo B12
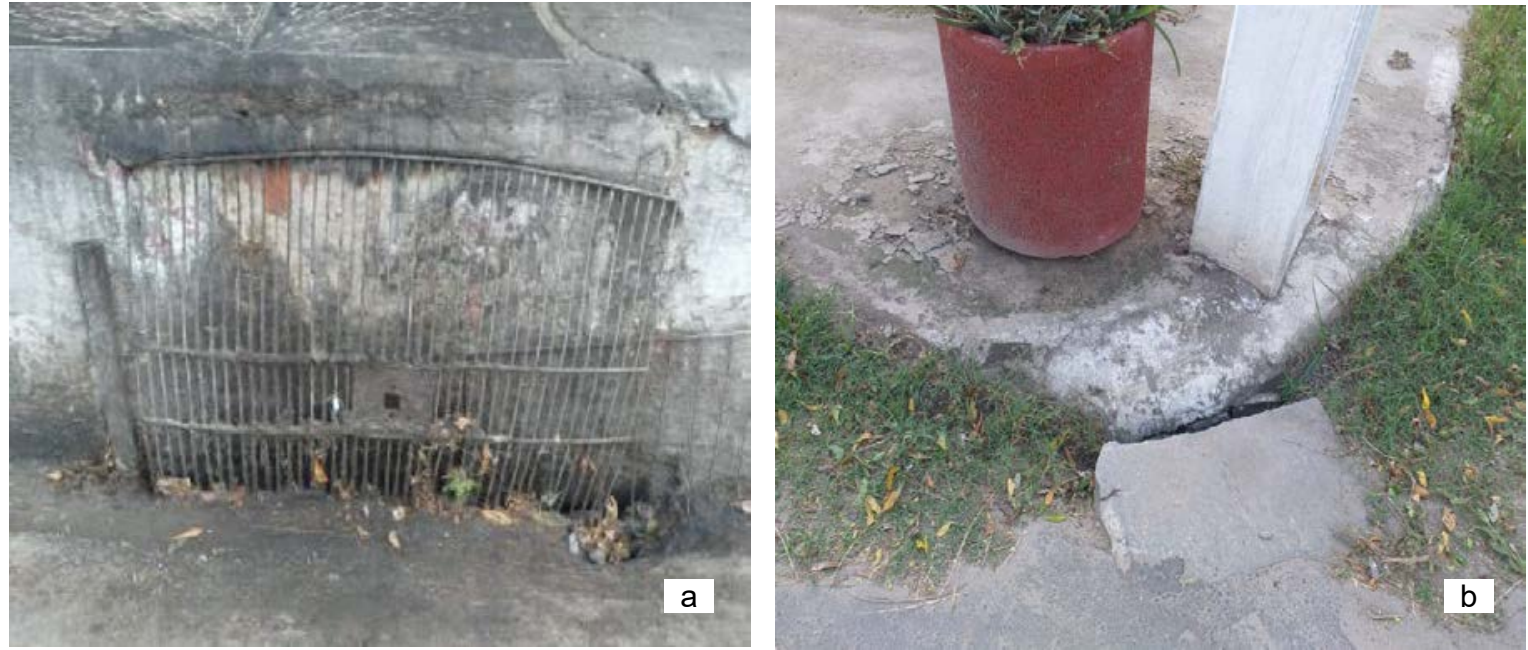

Fonte: Os autores (2019).

Os resultados encontrados na avenida José Caetano, em Quixadá/CE, corroboram com o estudo feito por Medau (2018) que, ao fazer uma análise de uma via, em Anápolis/GO, que apresentava mal funcionamento dos dispositivos de drenagem, concluiu que havia problemas em quase todas as bocas de lobo encontradas, estando quebradas ou com presença de lixo e, consequentemente, não funcionando de forma prevista no projeto. Problemas como esses, encontrados em ambos os estudos, infelizmente, são recorrentes no nosso país.

Com o exposto acima, não se pode atribuir os alagamentos apenas levando em consideração o estado de conservação dos dispositivos de drenagem da via, no entanto é notório que o estado em que as bocas de lobo se encontram não são eficazes como seriam caso estivessem em um estado de conservação melhor. 


\subsection{Estratégias propostas}

Para solucionar ou mitigar os alagamentos que causam transtornos durante e após as chuvas, além da manutenção dos dispositivos de drenagem já existentes, faz se necessária a adoção de medidas integradas aos projetos atuais, que tenham comprometimento com o meio ambiente.

No contexto no qual está inserido este trabalho, é possível compensar o impacto gerado pela urbanização com alternativas tecnológicas adotadas pelas denominadas LID - Low Impact Development, que são atuais formas sustentáveis que buscam condições semelhantes às de pré-ocupação para manejo das águas urbanas pluviais.

\subsubsection{Pavimentação permeável}

Com a adoção de pavimentos permeáveis, há uma redução do volume de escoamento superficial e no impacto da qualidade da água, já que esse recebe o escoamento gerado em sua superfície e também pode receber o escoamento superficial proveniente de outras áreas. Por serem preenchidos com vegetação, os cuidados que devem ser tomados são os cuidados nos períodos de corte da vegetação, uma vez que os locais dos estacionamentos livres das ações dos pneus estão sujeitos ao crescimento excessivo.

Segundo a NBR 16416 (ABNT, 2015), recomenda-se que o nível do lençol freático esteja, no mínimo, a 0,6 m de distância da parte inferior da base do pavimento. Essa recomendação é importante para que as águas tenham uma camada de solo suficiente para percolar, sem prejudicar a capacidade do armazenamento do pavimento.

O pavimento permeável aconselhável para ser colocado na avenida em estudo é do tipo bloco de concreto vazado. A sugestão é colocar esse tipo de pavimento apenas no acostamento da via, como é proposto na Figura 12, em razão de os pavimentos permeáveis não suportarem esforços sofridos pela avenida.

Figura 12 - Pavimento permeável como sugestão de solução para os problemas de drenagem urbana

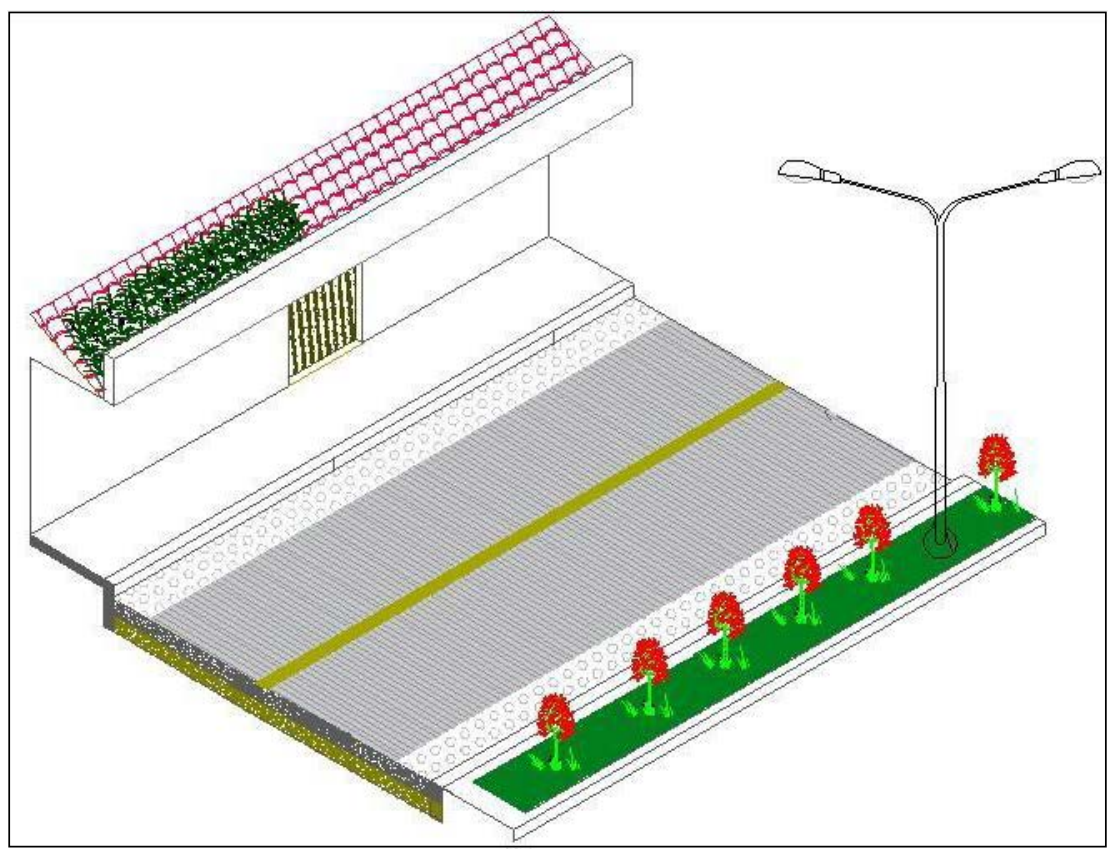

Fonte: Os autores (2019).

De acordo com estudos realizados por Araújo (2000), que retrata a simulação de vários pavimentos apresentados em sua investigação, o autor avalia o pavimento do tipo bloco de concreto vazado como altamente recomendado para o controle dos volumes escoados, em que as limitações identificadas estão 
relacionadas à necessidade de manutenção e ao maior custo por $\mathrm{m}^{2}$, porém o aumento do custo específico pode ser compensado pela redução da drenagem resultante da área, já que grande parte do volume se infiltrará, apresentando uma melhoria importante para alagamentos frequentes.

\subsubsection{Arborização urbana}

A criação de corredores verdes, como o exemplo mostrado na Figura 13, em calçadas ou no canteiro central da via, pode contribuir para minimizar os problemas de alagamentos que há na região, pois irá promover o aumento da permeabilidade do solo. Além disso, traz o conforto térmico proporcionado pelas copas das árvores, equilibra a evapotranspiração e reduz os níveis de poluição do ar e da poluição sonora.

Figura 13 - Exemplo de corredor verde instalado no Município Santa Clara do Sul - RS

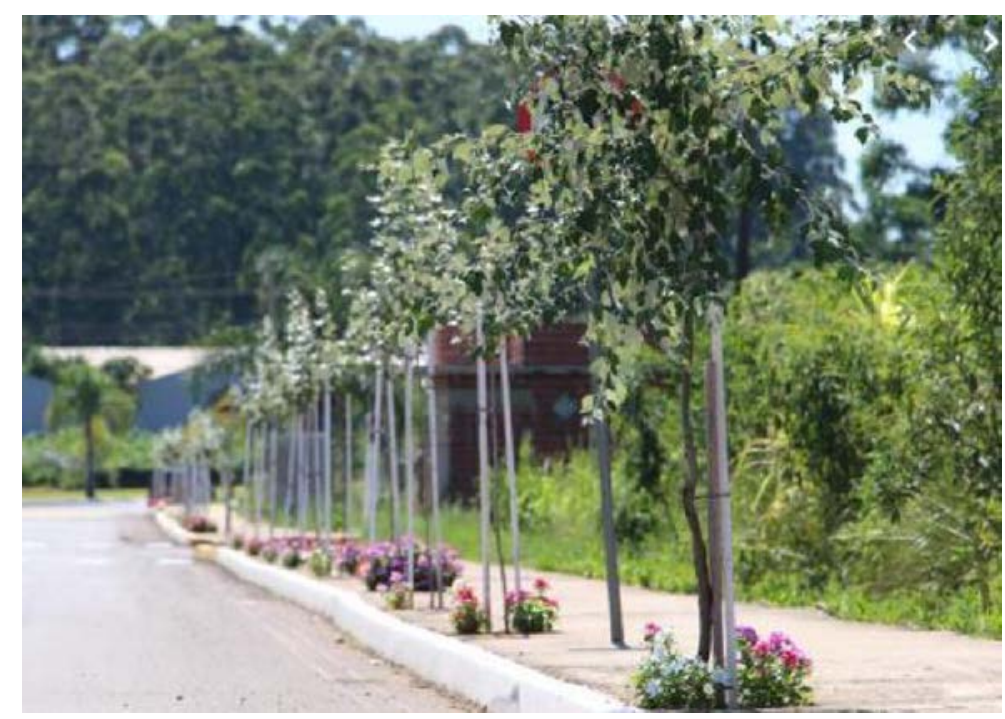

Fonte: Portal Região dos Vales (2018).

\subsubsection{Telhados verdes}

Além das contribuições hidrológicas que reduzem o custo de implantação das redes de drenagem e ajudam no escoamento superficial dentro das cidades, a utilização dos telhados verdes fornece diversos outros benefícios, que não foram avaliados neste estudo, mas citados por outros autores, como o conforto térmico e acústico, a contribuição para a redução do efeito estufa e a estabilidade térmica.

O telhado verde possui diversas características de uma melhor inserção no mundo atual, tanto para os lugares quentes quanto para os lugares frios. A Figura 14 mostra a indicação do telhado verde com vista lateral para melhorar as condições da avenida José Caetano de Almeida. 
Figura 14 - Detalhe do telhado verde proposto para a área em estudo e vista lateral

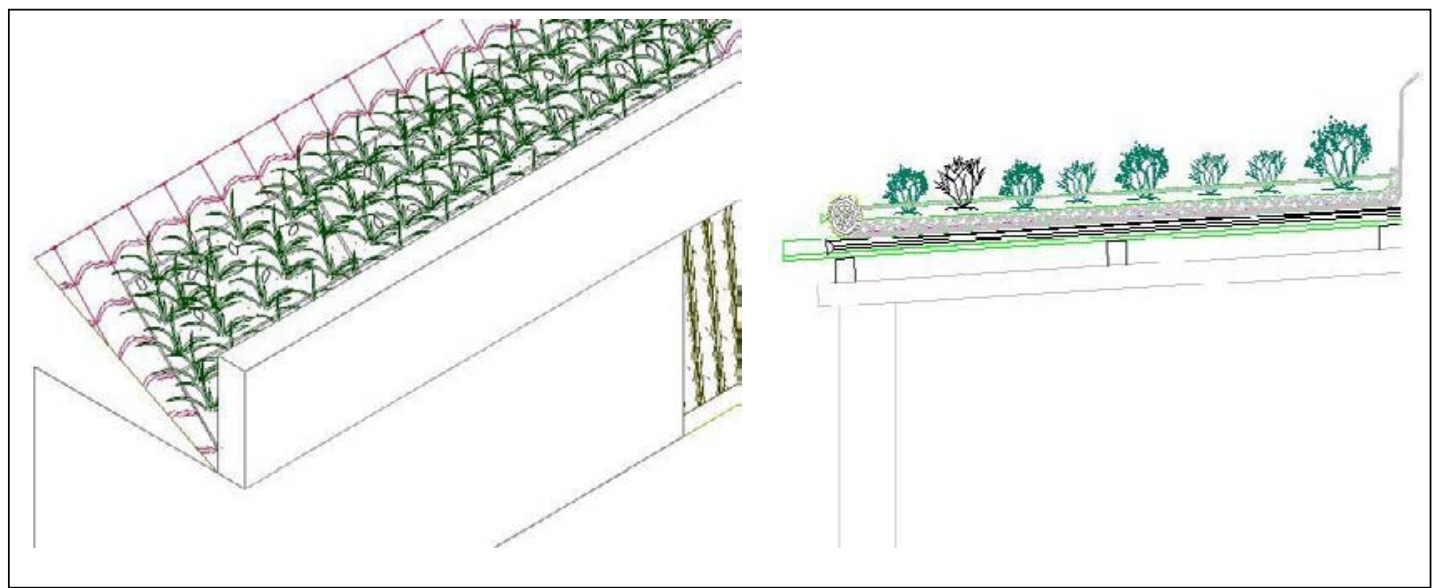

Fonte: Os autores (2019).

É possível observar a Avenida José Caetano de Almeida na Figura 15, com todos os seus defeitos de pavimentação, além dos defeitos de drenagem já mostrados anteriormente. Com isto, é apresentada a proposta completa para a via na Figura 16, que traz o pavimento permeável nos acostamentos e próximo ao canteiro central, com complementação do corredor verde no próprio canteiro e revitalização da via, além do telhado verde para um melhor escoamento superficial, que irão evitar alagamentos e enchentes urbanas recorrentes na avenida.

Figura 15 - Vista frontal atual da avenida José Caetano de Almeida

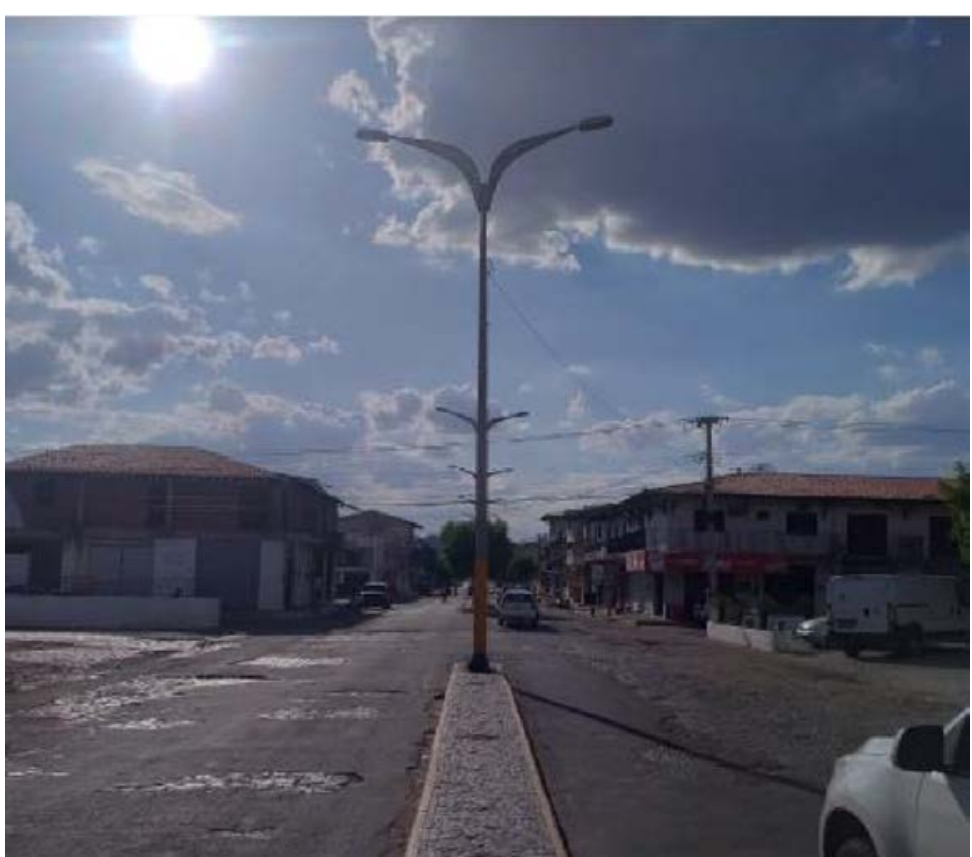

Fonte: Os autores (2019). 
Figura 16 - Vista frontal da proposta da via.

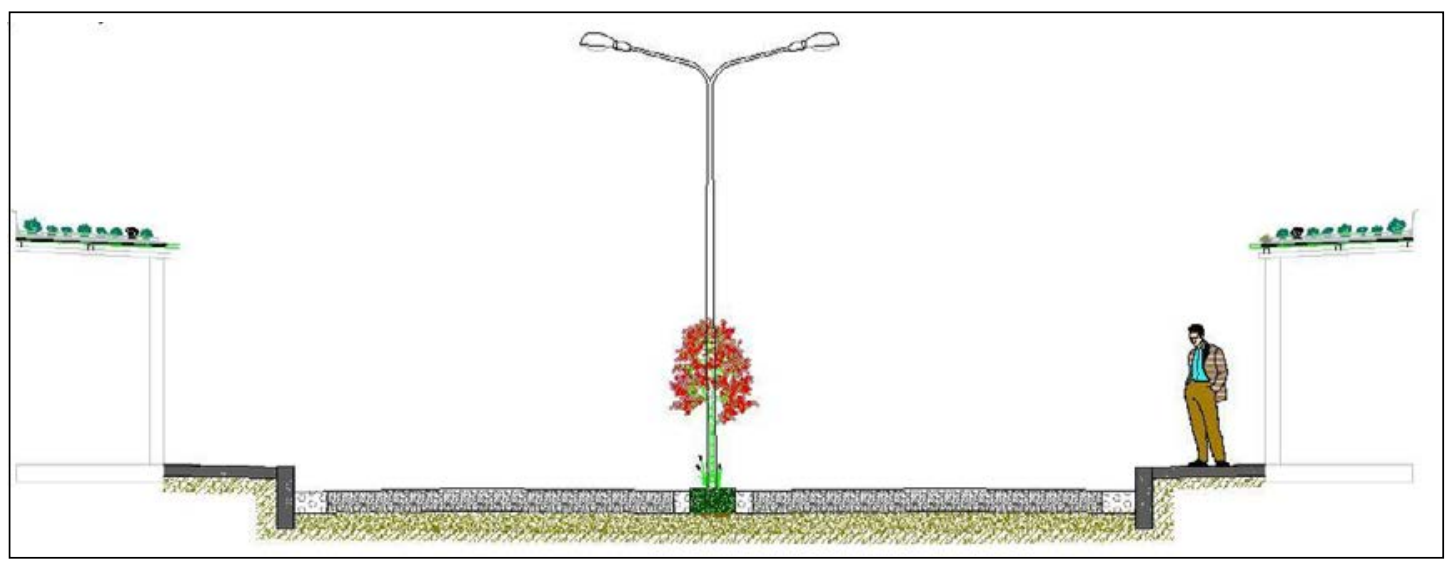

Fonte: Autores (2019).

O telhado verde é uma alternativa viável e eficiente, além de ter efeito estético, bem como o seu sistema físico construtivo e suas soluções para o conforto ambiental, evidenciando a importância da utilização de técnicas compensatórios, principalmente em grandes empreendimentos residenciais ou industriais.

\section{Conclusão}

Na avenida José Caetano de Almeida foram observadas 15 bocas de lobo que, em sua maioria, apresentavam problemas, que fazem os dispositivos funcionarem de forma ineficiente, não garantindo as condições previstas no projeto. Essa realidade decorre de diversos fatores: negligência do poder público, mau uso do solo pelos moradores, falta de fiscalização e uso inadequado das redes de esgotamento sanitário e drenagem de águas pluviais.

Foi possível concluir que, para se obter um bom funcionamento de um sistema de drenagem de águas superficiais, é necessário padronizar e conservar os dispositivos de drenagem. Com isso, é recomendável a manutenção dos dispositivos da avenida José Caetano de Almeida, que é o aspecto mais importante quando se trata de microdrenagem

Ao compreender como funciona a urbanização e seus impactos, pode-se compreender as atuais dificuldades e falhas vistas e analisadas na avenida em estudo. Sendo assim, faz-se necessária a conscientização e intervenção da prefeitura para fazer manutenções regulares e campanhas para conscientização da população sobre o acúmulo de lixo, que contribui para o deteriorando do sistema de drenagem.

Com a realização da ampliação de áreas verdes, para melhorar o processo de infiltração da água da chuva no solo, unindo o planejamento e controle do uso do solo ao ordenamento do território, pode haver uma grande melhoria na região da avenida José Caetano de Almeida. Porém é necessário que haja atualização imediata do Plano Diretor da cidade.

\section{Referências}

ARAÚJO, S. R. As funções dos telhados verdes no meio urbano, na gestão e no planejamento de recursos hídricos. 2007. Trabalho de Conclusão de Curso. (Bacharelado em Engenharia Florestal) Instituto de Florestas, Universidade Federal Rural do Rio de Janeiro, Seropédica, 2007.

ASSOCIAÇÃO BRASILEIRA DE NORMAS TÉCNICAS. ABNT NBR 16.416: pavimentos permeáveis de concreto- requisitos e procedimentos. Rio de Janeiro: ABNT, 2015. 
BRASIL. Lei $n^{\circ} .11 .445$ de 5 de janeiro de 2007. Diretrizes nacionais para o saneamento básico. Altera as Leis nos 6.766, de 19 de dezembro de 1979, 8.036, de 11 de maio de 1990, 8.666, de 21 de junho de 1993, 8.987, de 13 de fevereiro de 1995, revoga a Lei no 6.528, de 11 de maio de 1978, e dá outras providências. Brasília, 2007.

CEARÁ. Assembleia do Estado do Ceará. Caderno regional da sub-bacia do Banabuiú. Fortaleza: INESP, 2009. Disponível em: http://portal.cogerh.com.br/wp-content/uploads/2018/09/Bacia-doBanabui\%C3\%BA.pdf. Acesso: em 17 jun. 2019.

CEARÁ. Assembleia Legislativa do Estado do Ceará. Pactos das águas. Fortaleza: INESP, 2009.

CLIMATE-DATA.ORG. Clima Quixadá. Disponível em: https://pt.climate-data.org/america-do-sul/brasil/ ceara/quixada-25752/. Acesso: em 15 nov. 2019.

CHUVA em Quixadá transforma ruas em rios, isola bairros e alaga casas. Diário do Nordeste, Fortaleza, 6 mar., 2017. Disponível em: http://blogs.diariodonordeste.com.br/sertaocentral/meteorologia/chuva-de100mm-causa-alagamentos-e-transtornos-em-varios-bairros-de-quixada/50318. Acesso: em 9 de jun. 2019.

DRUMOND, P. P. Estudo da influência da reservação de águas pluviais em lotes do município de Belo Horizonte, MG: avaliação hidráulica e hidrológica. 2012. Dissertação (Mestrado em Saneamento, Meio Ambiente e Recursos Hídricos) - Universidade Federal de Minas Gerais, Belo Horizonte, 2012.

IBGE. Norte e Nordeste convivem com restrições no acesso a saneamento básico. Rio de Janeiro: IBGE, 2018. Disponível em: www.agenciadenoticias.ibge.gov.br/agencia-notícias. Acesso: em 25 abr. 2019.

IBGE. Pesquisa nacional de saneamento básico. Rio de Janeiro: IBGE, 2008. Disponível em: www.ibge. gov.br/estatisticas/multidominio. Acesso: em 25 abr. 2019.

IBGE. Quixadá: população estimada. Rio de Janeiro: IBGE, 2019. Disponível em: https://www.ibge.gov.br/ cidades-e-estados/ce/quixada.html. Acesso: em 25 set. 2019.

IBGE. Quixadá: território e ambiente, esgotamento sanitário adequado. Rio de Janeiro: IBGE, 2010. Disponível em: https://cidades.ibge.gov.br/brasil/ce/quixada/panorama. Acesso em: 25 set. 2019.

INSTITUTO DE PESQUISA E ESTRATÉGIA ECONÔMICA DO CEARÁ. Perfil municipal de Quixadá. Fortaleza: IPECE, 2017. Disponível em: https://www.ipece.ce.gov.br/wp-content/uploads/sites/45/2018/09/ Quixada_2017.pdf. Acesso em: 17 nov. 2019.

MEDAU, I. Análise dos dispositivos de drenagem urbana na avenida São Francisco Anápolis - Go. 2018. Trabalho de Conclusão de Curso (Graduação em Engenharia Civil) - UNIEVANGÉLICA, Anápolis, 2018.

MUNICÍPIO. Desenvolve projeto de corredores verdes. Disponível em: http://www.regiaodosvales.com. br/municipio-desenvolve-projeto-de-arborizacao-urbana/. Acesso: em: 19 out. 2019.

QUIXADÁ. Prefeitura de Quixadá. Plano Diretor da Cidade de Quixadá-Ce. 2000.

SANTOS, M. A urbanização brasileira. São Paulo, Hucitec, 1998.

TUCCI, C. E. M. Águas urbanas. Estudos Avançados, [S. I.], v. 22, n. 63, p. 97-112, 2008.

20 MINUTOS de chuvas em Quixadá deixa ruas alagadas e estradas prejudicadas. Sertão alerta. Quixadá, 5 dez. 2018. Disponível em: http://www.sertaoalerta.com.br/05/12/2018/20-minutos-de-chuvas-em-quixadadeixa-ruas-alagadas-e-estradas-prejudicadas/. Acesso: em 9 jun. 2019. 


\section{Sobre os autores}

\section{Clarissa Patrizia de Melo Freitas Almeida}

Graduanda de Engenharia civil na Faculdade Cisne de Quixadá. Estagiária da Secretaria de Desenvolvimento Urbano da cidade de Quixadá.

\section{José Wémenson Rabelo Chaves}

Graduando de Engenharia civil na Faculdade Cisne de Quixadá. Monitor nas disciplinas de Cálculo I e Geotécnica II 2018-2019. Técnico em Informática, CENTEC - 2015. Áreas de atuação: geotecnia, estradas e materiais, especificamente em estradas não pavimentadas.

\section{Maria Jorgiana Ferreira Dantas}

Doutorado em Agronomia pela Universidade Estadual Paulista Júlio de Mesquita Filho - Unesp, Faculdade de Ciências Agronômicas - 2013. Bolsista de doutorado sanduiche pela Capes na Universidad de Valência/Espanha. Possui graduação em Recursos Hídricos/Saneamento Ambiental pela Faculdade de Tecnologia CENTEC-Cariri - 2008. Mestrado em Engenharia agrícola pela Universidade Federal do Ceará - 2010. Tem experiência na área de saneamento ambiental, engenharia agrícola, sensoriamento remoto e expressão gráfica com ênfase em recursos hídricos e geoprocessamento ambiental.

Recebido em: 20.04.2020

Aceito em: 01.06.2020 